\title{
Níveis de Energia na Dieta para Bubalinos em Crescimento Alimentados em Confinamento. 1. Desempenho e Bioquímica de Nutrientes Sangüíneos ${ }^{1}$
}

\author{
Raul Franzolin ${ }^{2}$, Juliano Roberto da Silva ${ }^{3}$, Dario Ocampos ${ }^{4}$
}

\begin{abstract}
RESUMO - Vinte e sete bubalinos em crescimento da raça Mediterrâneo foram mantidos em confinamento por cerca de 140 dias, visando avaliar os efeitos de diferentes níveis de energia ingerida sobre o desempenho e as concentrações de glicose, proteína total e uréia no sangue. Os tratamentos constituíram de três níveis de ingestão de energia: BE (Baixa Energia), RE (Requerida Energia) e AE (Alta Energia). RE foi calculado com $125 \mathrm{kcal} / \mathrm{kg}^{0,75} /$ dia de energia metabolizável para mantença; BE com $20 \%$ abaixo e AE com $20 \%$ acima desse nível, adotando-se ganho diário médio de $800 \mathrm{~g}$, correspondendo a $10 \mathrm{kcal}$ de EM/g de ganho para animais até $250 \mathrm{~kg}$ e mais $0,02 \mathrm{kcal} / \mathrm{kg}$ de peso acima de $250 \mathrm{~kg} / \mathrm{g}$ de ganho. Amostras de sangue foram colhidas em três períodos, ou seja, 44,66 e 88 dias após o início do experimento. Houve diferenças significativas no ganho de peso médio diário entre BE (773,9 g), RE (942,8 g) e AE (1071,8 g) e nos níveis de uréia no soro. As ingestões médias de matéria seca ( $\left.\mathrm{g} / \mathrm{kg}^{0,75}\right)$ e de energia metabolizável estimadas (Mcal/animal/dia) foram, respectivamente: 89,54 e 17,13 para BE, 92,87 e 18,24 para RE e 95,66 e 20,94 para AE. Com base no ganho de peso obtido e na quantidade diária de energia metabolizável ingerida, concluiu-se que o requerimento de energia metabolizável total para bubalinos em crescimentos recomendado por KEARL (1982) encontra-se superestimado em média de 14,73\%.
\end{abstract}

Palavras chave: bubalinos, confinamento, desempenho, energia, requerimentos

\section{Energy Levels in the Diet for Growing Buffaloes under Feedlot. 1. Performance and Biochemical Blood Nutrients}

\begin{abstract}
Twenty-seven growing buffaloes of Mediterranean breed were maintained in feedlot for about 140 days with the objective to evaluate the effects of energy intake on the performance and blood serum concentrations of glucose, total protein and urea. The treatments were constituted of three different levels of energy intake: LE (Low Energy), RE (Required Energy) and HE (High Energy). RE was calculated with $125 \mathrm{kcal} / \mathrm{kg}^{0.75} /$ day of metabolizable energy for maintenance; LE with $20 \%$ below and HE with $20 \%$ above of this level, adopting gain average daily of $800 \mathrm{~g}$, corresponding to $10 \mathrm{kcal}$ of EM/g of gain for animal up to $250 \mathrm{~kg}$ plus $0.02 \mathrm{kcal} / \mathrm{kg}$ of weight above $250 \mathrm{~kg} / \mathrm{g}$ of gain. Blood samples were collected in three periods: 44, 66 and 88 days after beginning of the experiment. There were significant differences in the average weight daily gain among LE (773.9 g), RE (942.8 g) and HE (1071.8 g) and urea blood serum level. Average dry matter intake $\left(\mathrm{g} / \mathrm{kg}^{0.75}\right)$ and metabolizable energy estimated (Mcal/animal/day) were, respectively: 89.54 and 17.13 to LE, 92.87 and 18.24 to RE and 95.66 and 20.94 to HE. Based on the obtained weight gain and metabolizable energy daily quantity ingested, it was concluded that the total requirement of metabolizable energy for growing buffaloes recommended by KEARL (1982) finds overestimated on an average of $14.73 \%$.
\end{abstract}

Key Words: buffalo, energy, feedlot, performance, requirement

\section{Introdução}

Na formulação de uma dieta para ruminantes, é importante que os requerimentos de energia e proteína para mantença e produção dos animais estejam mais próximos possíveis da realidade, com base nas condições em que estão sendo criados. As tabelas especializadas de requerimentos das diversas espécies animais ainda apresentam falhas, haja vista a ampla variabilidade de fatores envolvidos na obtenção dos dados. Assim, os valo- res médios são constantemente reavaliados em diversas condições de alimentação e ambientais para as diferentes espécies de ruminantes. $\mathrm{Na}$ literatura, há uma falta de informação sobre dados essenciais para o conhecimento das exigências nutritivas obtidos especificamente com bubalinos. A espécie bubalina é uma das mais carentes na adoção de valores médios de requerimentos nutritivos para os diferentes tipos de produção.

As formulações modernas de rações para ruminantes baseiam-se em cálculos feitos a partir da

\footnotetext{
1 Trabalho financiado pela FAPESP.

2Professor Titular do Departamento de Zootecnia da FZEA/USP - Campus da USP, 13695-900 - Pirassununga - SP. Email: rfranzol@usp.br

${ }^{3}$ Bolsista de Iniciação Científica do PIBIC/CNPq.

${ }^{4}$ Professor Associado do Departamento de Ciências Básicas da FZEA/USP.
} 
concentração energética da ração e da demanda de nitrogênio pelos microrganismos do rúmen para síntese de proteína microbiana. Portanto, deve-se saber qual a concentração energética da dieta capaz de maximizar o metabolismo ruminal para cada categoria animal e tipo de produção e, conseqüentemente, aumentar a produtividade animal.

Vários fatores afetam os requerimentos de energia em ruminantes: espécie animal, raça, sexo, tamanho e peso corporal, idade, estado físiológico (gestação, crescimento etc), tipo de produção e fatores de estresse do ambiente (temperatura, ventos, necessidades de água e sombra), entre outros (AGRICULTURAL RESEARCH COUNCIL ARC, 1980; AGRICULTURAL AND FOOD RESEARCH COUNCIL - AFRC, 1995). KEARL (1982) recomenda para mantença de bubalinos o valor médio de $125 \mathrm{kcal}$ de energia metabolizável/

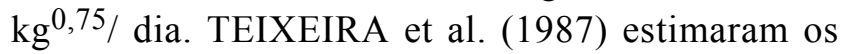
requerimentos diários de energia líquida, também para manutenção de bubalinos, como $78 \mathrm{kcal} \mathrm{de}$ energia líquida $/ \mathrm{kg}^{0,75}$. Segundo o Cornell Net Carbohydrate and Protein System (CNCPS), a exigência de energia líquida para mantença de bovinos é de $77 \mathrm{kcal} / \mathrm{kg}^{0,75}$ (SNIFFEN et al., 1992) e o NATIONAL RESEARCH COUNCIL - NRC (1989) trabalha com o valor de $86 \mathrm{kcal} / \mathrm{kg}^{0,75}$ para bovinos em crescimento. As exigências energéticas para ganho em peso variam com a composição corporal devido ao aumento de peso dos animais em crescimento. Portanto, devem-se ajustar os requerimentos dos animais ao longo do tempo, principalmente com os animais em confinamento.

A regulação do consumo de alimentos pelos animais é um processo complexo que se realiza por meios fisiológicos e físicos. As limitações físicas do trato gastrintestinal promovem queda no consumo, quando os animais estão sob dieta de volumosos de baixa qualidade, enquanto o nível de energia no rúmen limita o consumo de matéria seca em rações de alta qualidade e com baixa densidade mais do que o teor de proteína associado a outros fatores (CHURCH e POND, 1977).

Segundo MINSON et al. (1976), o nível da produção animal em pastagem é basicamente determinado pela ingestão diária de energia líquida, mas os limites máximos de ingestão e de desempenho animal somente serão atingidos quando a dieta contiver suficientes quantidades de proteínas, minerais e vitaminas.
Várias pesquisas têm sido desenvolvidas com bubalinos em confinamento, avaliando o desempenho, consumo e a conversão alimentar em diversos sistemas de alimentação. DRUDI et al. (1976) trabalharam com bubalinos Murrah em confinamento durante 131 dias, onde os animais receberam uma ração composta de $70 \%$ de silagem de colonião (Panicum maximum Jacq.), 20\% de esterco de galinhas poedeiras e $10 \%$ de rolão de milho, apresentando consumo médio diário de matéria seca de $9,25 \mathrm{~kg}$, representando cerca de $2,9 \%$ do peso vivo médio. VILLARES et al. (1979) verificaram em 37 bubalinos submetidos ao "feeding test" um peso vivo médio, aos 140 dias, de $378,20 \mathrm{~kg}$, consumindo, em média 10,2 kg de ração a base de feno de capim gordura (Melinis minutiflora) diariamente por animal, correspondendo a $2,71 \%$ de seu peso, com conversão de $10,52 \mathrm{~kg}$ de ração/ $\mathrm{kg}$ de ganho de peso. LORENZONI et al. (1986) desenvolveram experimento com 30 bovídeos pertencentes a seis grupos genéticos diferentes, bubalinos, nelores, holandeses e mestiços holandês x zebu (1/2; $3 / 4$ e 5/8). Os bubalinos apresentaram consumo diário médio de 8,94 kg de MS, sendo ligeiramente superior aos demais grupos mas levemente inferior em porcentagem do peso corporal $(2,46 \%)$, exceto para os nelores. VELLOSO et al. (1994) verificaram ganho de peso diário de 1,03 para bubalinos em confinamento, consumindo em média $91,39 \mathrm{~g} \mathrm{MS} / \mathrm{kg}^{0,75}, 1,10 \mathrm{~kg}$ de proteína bruta e $5,08 \mathrm{~kg}$ de nutrientes digestíveis totais. KEARL (1982) após ampla revisão sobre o assunto, adotou o valor médio de $97,4 \mathrm{~g} \mathrm{MS} / \mathrm{kg}^{0,75}$ para a ingestão de matéria seca para bubalinos em crescimento, calculado para uma concentração energética da ração de 2,5 Mcal de energia metabolizável/kg MS. JORGE et al. (1997) estudaram o desempenho e consumo alimentar em quatro grupos genéticos de animais abatidos em dois estágios de maturidade, sendo avaliados entre eles oito bubalinos mediterrâneos. Os animais foram alimentados com ração contendo 50\% de concentrado e os autores observaram que os bubalinos apresentaram em média $1,30 \mathrm{~kg}$ de ganho de peso corporal vazio com uma ingestão diária de matéria seca de $9,61 \mathrm{~kg}$, equivalendo a $106,08 \mathrm{~g} / \mathrm{kg}^{0,75}$ e 2,36\% do peso corporal vazio. RODRIGUES et al. (2000) avaliaram o desempenho de 12 bubalinos mestiços Jafarabadi em confinamento durante 100 dias consumindo ração com $40 \%$ de concentrado. Os animais tiveram ganho de peso médio diário de $940 \mathrm{~g}$ /animal ingerindo 9,26 kg MS, equivalendo a $116,06 \mathrm{~g} / \mathrm{kg}^{0,75} \mathrm{e}$ conversão alimentar de $10,04 \mathrm{~kg} \mathrm{MS} / \mathrm{kg}$ de ganho. 
Animais jovens e com rápido crescimento consomem mais alimentos por unidade de tamanho que os animais adultos, especialmente sob dieta rica em volumoso de alta qualidade.

O presente trabalho teve por objetivo avaliar três níveis de energia ingerida por bubalinos em crescimento, alimentados em regime de confinamento, através das determinações do desempenho, consumo alimentar, níveis séricos de proteína total, uréia e glicose.

\section{Material e Métodos}

Vinte e sete bubalinos da raça Mediterrâneo, sendo 18 machos e 9 fêmeas, com idade média variando entre 418 a 527 dias e peso vivo entre 203 a $389 \mathrm{~kg}$ foram identificados, higienizados e alojados em confinamento, mantendo-se nove animais em baias individuais e nove baias com dois animais cada. Durante as primeiras 4 semanas, eles permaneceram em período de adaptação às instalações e manejo geral, recebendo dieta de feno de capim coastcross (Cynodon dactylon) à vontade mais $1 \mathrm{~kg}$ de concentrado por animal/dia.

Após o período de adaptação, três grupos de animais com seis machos e três fêmeas cada foram alimentados com três níveis diferentes níveis de energia: BE (baixa energia), RE (requerida energia) e AE (alta energia). RE foi calculado de acordo com o requerimento diário de energia para mantença de bubalinos em crescimento de $125 \mathrm{kcal} \mathrm{EM} / \mathrm{kg}^{0,75}$. O nível $\mathrm{BE}$ com $20 \%$ abaixo do nível de mantença e o AE com $20 \%$ acima. Para estimativa do requerimento energético para ganho de peso, adotou-se um ganho médio diário de $800 \mathrm{~g}$, correspondendo a $10 \mathrm{kcal}$ de EM para animais até $250 \mathrm{~kg}$ e mais $0,02 \mathrm{kcal} / \mathrm{kg}$ de peso acima de $250 \mathrm{~kg} / \mathrm{g}$ de ganho, conforme recomendações de KEARL (1982).

As rações foram formuladas com feno de capimcoastcross como volumoso e, milho em grãos moídos e farelo de soja, como concentrado. Os níveis de energia metabolizável consumidos foram calculados de acordo com os teores médios de EM dos ingredientes citados para bubalinos por KEARL (1982) e apresentados na Tabela 1. Amostras dos ingredientes foram colhidas durante todo o período experimental e determinadas as suas composições bromatológicas. A fim de se obter o máximo controle possível da quantidade de energia ingerida pelo animal, de acordo com os níveis de energia dos tratamentos, foram utilizados três níveis de concentração energética na ração: baixo, médio e alto, mantendo-se o nível de concentrado em $60 \%$, no máximo. A cada três semanas, as rações eram recalculadas em função do novo peso do animal, aumentando-se a quantidade da dieta ou a concentração energética da ração, para garantir o nível de ingestão de energia desejável.

Os animais foram pesados a cada 21 dias e os machos permaneceram no experimento até atingirem o peso de abate de 450 a $500 \mathrm{~kg}$ e as fêmeas até o final do período experimental que foi de 147 dias. As pesagens foram padronizadas com os bubalinos permanecendo em dieta hídrica por período mínimo de 12 horas antes das pesagens.

A quantidade diária total das rações, foi oferecida dividida em duas partes iguais, às 7 e $15 \mathrm{~h}$. De manhã, pesavam-se as sobras de cada baia, fornecendo-se, em seguida, o concentrado e aproximadamente 40 minutos após, colocava-se o feno. Os animais tiveram livre acesso a uma mistura completa de sal mineral e água através de bebedouros automáticos. Nas baias com dois animais, as rações foram colocadas separadas nos cantos dos cochos e o consumo individual foi considerado a média para os dois animais.

Amostras de soro sangüíneo de todos os animais foram colhidas com 44, 66 e 88 dias após o início do experimento em tubos esterilizados de vacumtainer e analisadas para concentração de glicose pelo método colorimétrico (Kit Glicose E enzimática - CELM ${ }^{\circledR}$ ), proteína total (Kit ALDRICH $®)$ e uréia (Kit Enzimático Color- DOLES () .

Os dados obtidos foram analisados estatisticamente pela análise de variância para experimento inteiramente aleatório (ZAR, 1984) com o cálculo da estatística F e de seu respectivo "p-value". Nos casos em que $\mathrm{p}<0,05$, as médias dos tratamentos foram comparadas pelo teste de Tukey.

$\mathrm{Na}$ análise estatística para ganho de peso total (GPT), foi considerado o ganho de peso no período de 105 dias de confinamento com todos os 27 animais. A medida que os machos foram sendo abatidos, os dados de ganho foram incluídos na análise para avaliação do ganho de peso diário (GPD).

A análise de perfil (MORRISON, 1967) foi utilizada para as variáveis, níveis sorológicos de glicose, proteína total e uréia, avaliadas em três momentos de colheitas. Foram testadas as hipóteses de: a) interação entre grupos e momentos, visando verificar se o perfil dos três grupos poderia ser considerado similar; b) efeito de tratamento, visando comparar os três grupos 
no conjunto dos tempos, ou seja, se os perfis dos três grupos diferiram no conjunto dos três momentos; c) efeitos de tempo, visando verificar diferenças entre as médias dos momentos.

As análises foram desenvolvidas em computador no Centro de Computação da Faculdade de Medicina Veterinária e Zootecnia da UNESP, Campus de Botucatu e com o uso de programa de estatística (STATSOFT, 1995).

\section{Resultados e Discussão}

As composições bromatológicas dos ingredientes utilizados nas rações encontram-se na Tabela 1 . O feno de capim coastcross foi de baixa qualidade tendo em vista o seu baixo teor de proteína bruta $(6,26 \%)$ e alto teor de FDN $(75,65 \%)$. Os valores encontrados estão próximos aos valores citados por KEARL (1982) para o feno seco ao sol de Cynodon dactylon usado no continente asiático, exceto para o teor de fibra bruta que foram 10,42 unidades percentuais maiores.

Os desempenhos dos bubalinos alimentados nos três níveis de energia e os consumos médios de matéria seca estão apresentados na Tabela 2 . O peso médio dos animais dentro dos tratamentos não foi muito disperso, o que demonstra distribuição variada de pesos entre os lotes. Os animais alimentados com nível baixo em energia tiveram menor ganho total $(\mathrm{P}<0,05)$ que os demais grupos. Entretanto, houve ganho de peso diário crescente $(\mathrm{P}<0,05)$ com aumento do nível de energia na dieta, conforme esperado.

Apesar da concentração energética da ração e o nível de concentrado terem sido crescentes nas dietas BE, RE e AE, não houve diferenças significativas $(\mathrm{P}<0,05)$ na ingestão média diária total de matéria seca $(\mathrm{kg} / \mathrm{dia})$, mas o consumo de matéria seca em $\mathrm{g} / \mathrm{kg}^{0,75}$ e em porcentagem do peso vivo foi maior nos

Tabela 1 - Composições bromatológicas dos ingredientes utilizados nas rações, com base na matéria seca Table 1 - Proximal analyses of feedstuffs rations on dry matter basis

\begin{tabular}{|c|c|c|c|}
\hline \multirow[t]{2}{*}{ Itens $(\%)$} & \multicolumn{3}{|c|}{$\begin{array}{l}\text { Ingredientes } \\
\text { Feedsttufs }\end{array}$} \\
\hline & $\begin{array}{c}\text { Feno de capim coastcross } \\
\text { Coastcross grass hay }\end{array}$ & $\begin{array}{l}\text { Farelo de soja } \\
\text { Soybean meal }\end{array}$ & $\begin{array}{c}\text { Milho grãos } \\
\text { Corn grain }\end{array}$ \\
\hline Matéria seca & 90,54 & 88,04 & 86,67 \\
\hline Dry matter & & & \\
\hline Proteína bruta & 6,26 & 50,99 & 10,07 \\
\hline Crude protein & & & \\
\hline $\begin{array}{l}\text { Fibra bruta } \\
\text { Crude fiber }\end{array}$ & 33,32 & 6,52 & 1,95 \\
\hline $\begin{array}{l}\text { Extrato etéreo } \\
\text { Ether extract }\end{array}$ & 1,23 & 1,66 & 3,52 \\
\hline $\begin{array}{l}\text { Extrativos não nitrogenados } \\
\text { Free nitrogen extracts }\end{array}$ & 53,94 & 33,75 & 83,00 \\
\hline $\begin{array}{l}\text { Matéria mineral } \\
\text { Mineral matter }\end{array}$ & 5,25 & 7,09 & 1,45 \\
\hline $\begin{array}{l}\text { Cálcio } \\
\text { Calcium }\end{array}$ & 0,39 & 0,34 & 0,06 \\
\hline $\begin{array}{l}\text { Fósforo } \\
\text { Phosphorus }\end{array}$ & 0,13 & 0,56 & 0,13 \\
\hline $\begin{array}{l}\mathrm{FDN} \\
N D F\end{array}$ & 75,56 & - & - \\
\hline $\begin{array}{l}\text { FDA } \\
A D F\end{array}$ & 39,61 & - & - \\
\hline $\begin{array}{l}\text { Celulose } \\
\text { Cellulose }\end{array}$ & 35,69 & - & - \\
\hline $\begin{array}{l}\text { Lignina } \\
\text { Lignin }\end{array}$ & 7,00 & - & - \\
\hline $\begin{array}{l}\text { Energia bruta (Mcal/kg MS) } \\
\text { Crude energy (Mcal/kg DM) }\end{array}$ & 4,131 & 4,426 & 3,881 \\
\hline $\begin{array}{l}\text { Energia metabolizável }{ }^{1}(\mathrm{Mcal} / \mathrm{kg} \mathrm{MS}) \\
\text { Metabolize energy }\end{array}$ & 1,97 & 3,17 & 3,19 \\
\hline
\end{tabular}

${ }^{1}$ Energia metabolizável estimada para bubalinos conforme KEARL (1982).

${ }^{1}$ Metabolizable energy estimated to water buffalo according to KEARL (1982).

Rev. bras. zootec., 30(6):1872-1879, 2001 
animais que receberam o nível mais alto de energia $(95,79$ e 2,17) que o mais baixo $(89,60$ e 2,05), respectivamente. A ingestão média de matéria seca estimada para os bubalinos alimentados em AE, de $95,79 \mathrm{~g} \mathrm{MS} / \mathrm{kg}^{0,75}$ foi próxima à ingestão de $91,39 \mathrm{~g} /$ $\mathrm{kg}^{0,75}$ verificada por VELLOSO et al. (1994) em novilhos bubalinos sob confinamento alimentados com silagem de sorgo, milho e soja e àquela citada por KEARL (1982) para bubalinos em crescimento que é de $97,4 \mathrm{~g} / \mathrm{kg}^{0}, 75$ para uma concentração energética de 2,5 Mcal de energia metabolizável por kg de MS e inferior às observadas por JORGE et al. (1997) e RODRIGUES et al. (2000), que foram de 106,08 e $116,06 \mathrm{~g} / \mathrm{kg}^{0,75} /$ animal, respectivamente. A ingestão de matéria seca em porcentagem do peso corporal em todos os tratamentos foi inferior às observadas por DRUDI et al. (1976), VILLARES et al. (1979), LORENZONI et al. (1986) e JORGE et al. (1997) em bubalinos sob confinamento, que foram de 2,90; 2,71 ; 2,46; e 2,36\%, respectivamente. A ingestão média da mistura de sal mineral foi de 48,55 g/animal/dia. As rações ingeridas foram isoprotéicas com teor médio de $12,03 \%$ de PB.

A conversão alimentar foi melhor nos animais alimentados com níveis de energia mais elevados $\mathrm{AE}$ (7,74 kg MSI/kg ganho) e RE $(8,13)$ que os $\operatorname{BE}(9,76)$, provavelmente devido ao maior consumo de alimentos concentrados de maior valor nutritivo que o feno. A conversão encontrada no nível mais elevado de energia está próxima à observada por VELLOSO et al. (1994) de 7,92 em bubalinos alimentados com 4kg de concentrado por dia em regime de confinamento.

As estimativas dos requerimentos de energia dos animais com base nas estimativas da concentração de energia metabolizável dos ingredientes utilizados e nos ganhos de peso obtidos conforme apresentadas nas Tabelas 1 e 2, respectivamente, podem ser observadas na Tabela 3 . Para o total de energia metabolizável ingerida houve superestimativa média de $14,73 \%$ dos requerimentos recomendados para bubalinos em crescimento por KEARL (1982). Como não foi possível separar a quantidade de energia

Tabela 2 - Desempenho e consumo de matéria seca de bubalinos alimentados em confinamento Table 2 - Performance and dry matter intake of water buffalo fed in feedlot

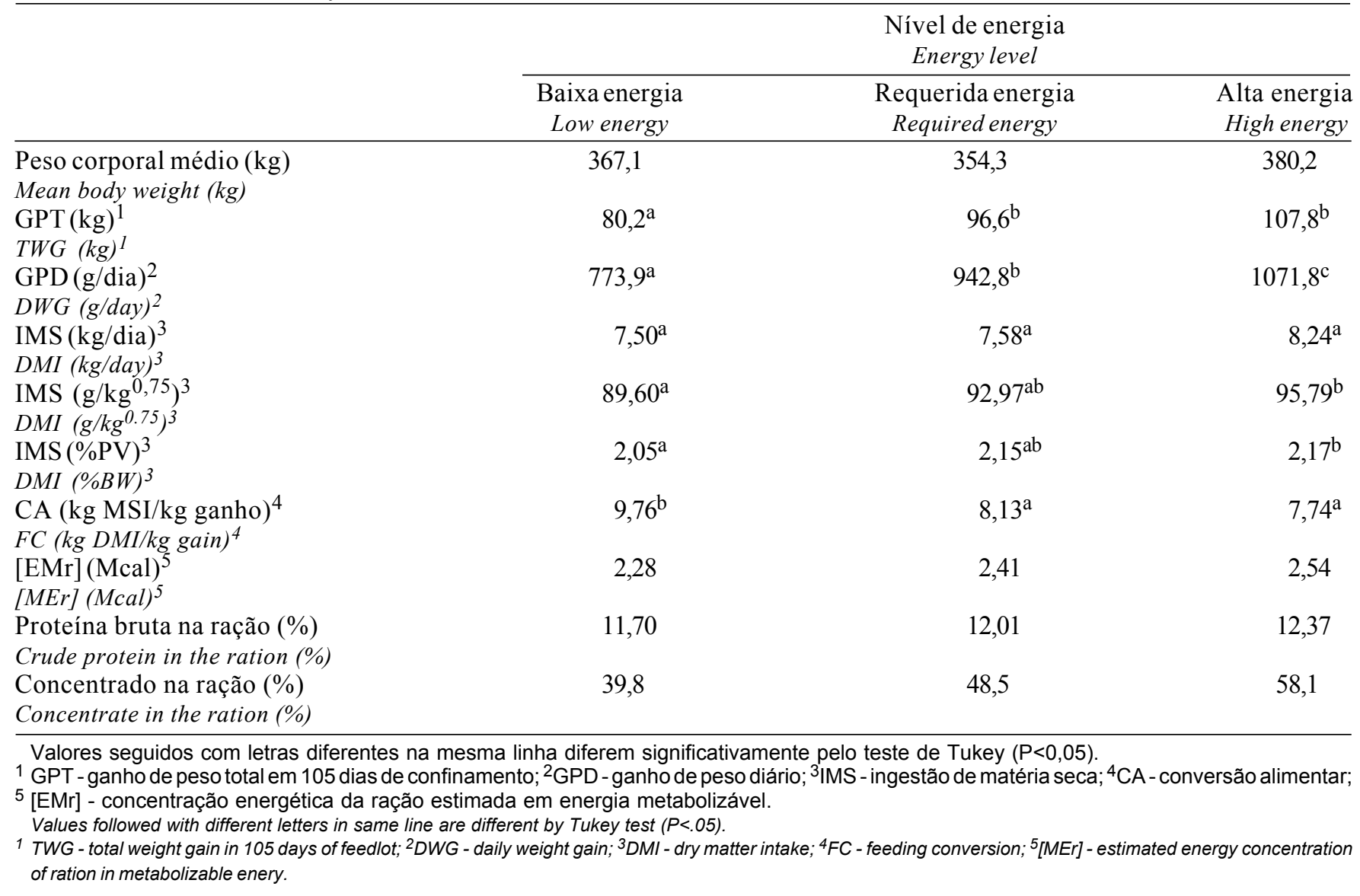


Tabela 3 - Estimativas dos requerimentos de energia para os bubalinos em crescimento em confinamento Table 3 - Estimated requirements of energy to growing water buffaloes in feedlot

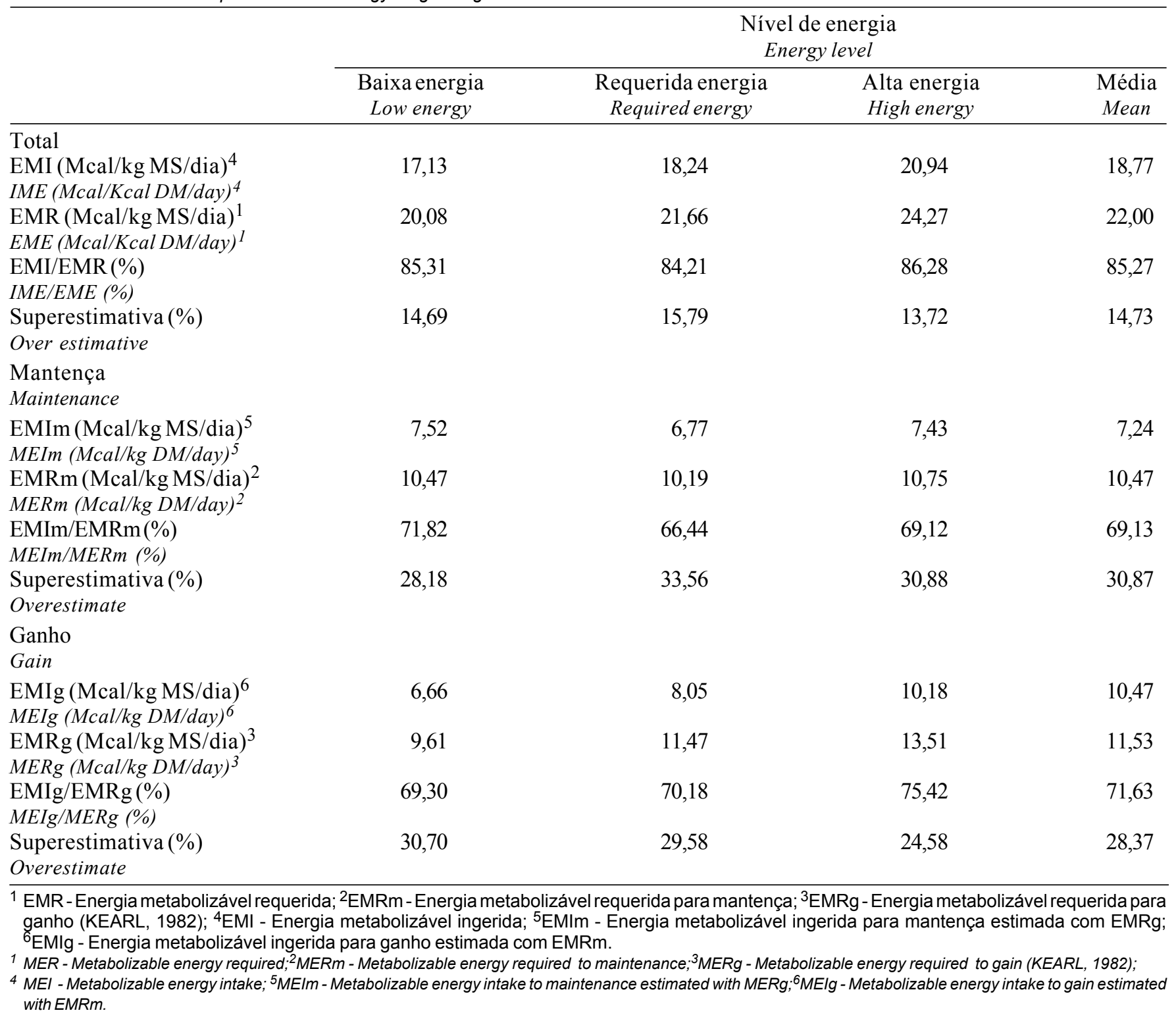

requerida para mantença ou para ganho de peso nas condições deste experimento, os requerimentos de energia de mantença e de ganho foram estimados fixando os valores para ganho e mantença recomendados pelo mesmo autor. Considerando que ambos os valores médios superestimados obtidos para mantença $(30,87 \%)$ e para ganho $(28,37 \%)$ possam estar elevados, possivelmente os dois requerimentos estão superestimados em relação aos recomendados por KEARL (1982). Estes achados estão de acordo com KHAN et al. (1988) que encontraram menor valor médio para requerimento de mantença de $108 \mathrm{kcal} \mathrm{EM} /$ $\mathrm{kg}^{0,75} /$ dia em bubalinos alimentados com rações a base de palhadas de trigo que aquele citado por KEARL (1982).

As concentrações de glicose, proteína total e uréia no sangue dos animais determinadas em três períodos de amostragem (momentos) podem ser observadas na Tabela 4. Não houve diferenças significativas $(P>0,05)$ entre os tratamentos no teor de glicose e proteína total, cujos teores médios foram 82,47 e 7,35 dL/100 mL, mas o teor de uréia diminuiu com o aumento do nível de energia dos animais, provavelmente devido à maior síntese de proteína microbiana com incorporação de amônia gerada da degradação da uréia com a maior disponibilidade de 
Tabela 4 - Concentrações médias de glicose, proteína total e uréia em amostras de soro sangüíneo coletadas em três períodos em bubalinos em confinamento sob dietas com três níveis de energia

Table 4 - Average concentrations of glucose, total protein and urea in serum blood samples collected in three periods in water buffaloes under feedlot fed diets with three energy levels

\begin{tabular}{|c|c|c|c|c|}
\hline & \multicolumn{3}{|c|}{$\begin{array}{l}\text { Nível de energia } \\
\text { Energy level }\end{array}$} & \multirow[b]{2}{*}{$\begin{array}{l}\text { Médic } \\
\text { Mean }\end{array}$} \\
\hline & $\begin{array}{l}\text { Baixa energia } \\
\text { Low energy }\end{array}$ & $\begin{array}{l}\text { Requerida energia } \\
\text { Required energy }\end{array}$ & $\begin{array}{l}\text { Alta energia } \\
\text { High energy }\end{array}$ & \\
\hline \multicolumn{5}{|c|}{$\begin{array}{l}\text { Glicose }(\mathrm{mg} / \mathrm{dL}) \\
\text { Glucose }(\mathrm{mg} / \mathrm{dL})\end{array}$} \\
\hline $\begin{array}{l}\text { Período } 44 \\
\text { Period } 44\end{array}$ & 67,00 & 82,55 & 76,75 & 75,43 \\
\hline $\begin{array}{l}\text { Período } 66 \\
\text { Period } 66\end{array}$ & 75,24 & 86,37 & 90,29 & 83,97 \\
\hline $\begin{array}{l}\text { Período } 88 \\
\text { Period } 88\end{array}$ & 84,55 & 91,41 & 88,07 & 88,01 \\
\hline $\begin{array}{l}\text { Média } \\
\text { Mean }\end{array}$ & 75,60 & 86,78 & 85,04 & 82,47 \\
\hline \multicolumn{5}{|c|}{$\begin{array}{l}\text { Proteína total }(\mathrm{g} / \mathrm{dL}) \\
\text { Total protein }(\mathrm{g} / \mathrm{dL})\end{array}$} \\
\hline $\begin{array}{l}\text { Período } 44 \\
\text { Period } 44\end{array}$ & 8,09 & 8,13 & 8,28 & 8,17 \\
\hline $\begin{array}{l}\text { Período } 66 \\
\text { Period } 66\end{array}$ & 7,64 & 7,91 & 7,83 & 7,79 \\
\hline $\begin{array}{l}\text { Período } 88 \\
\text { Period } 88\end{array}$ & 7,40 & 7,60 & 7,71 & 7,58 \\
\hline $\begin{array}{l}\text { Média } \\
\text { Mean }\end{array}$ & 7,71 & 7,88 & 7,94 & 7,85 \\
\hline \multicolumn{5}{|c|}{$\begin{array}{l}\text { Uréia }(\mathrm{mg} / \mathrm{dL}) \\
\text { Urea }(\mathrm{mg} / \mathrm{dL})\end{array}$} \\
\hline $\begin{array}{l}\text { Período } 44 \\
\text { Period } 44\end{array}$ & 21,06 & 18,02 & 16,76 & 18,61 \\
\hline $\begin{array}{l}\text { Período } 66 \\
\text { Period } 66\end{array}$ & 18,90 & 18,00 & 16,26 & 17,72 \\
\hline $\begin{array}{l}\text { Período } 88 \\
\text { Period } 88\end{array}$ & 19,07 & 17,36 & 14,94 & 17,12 \\
\hline $\begin{array}{l}\text { Média } \\
\text { Mean }\end{array}$ & $19,68^{\mathrm{a}}$ & $17,79^{b}$ & $15,99^{\mathrm{c}}$ & 17,82 \\
\hline
\end{tabular}

Valores seguidos com letras diferentes na mesma linha diferem significativamente entre si pelo teste Tukey $(P<0,05)$.

Valores com ausências de letras na mesma linha não diferem significativamente entre si $(P>0,05)$.

Values followed with different letters in same line are different by Tukey test $(P<.05)$.

Values with no letters in same line are no different by Tukey test $(P<.05)$.

energia para os microrganismos ruminais. Houve aumento significativo $(\mathrm{P}<0,05)$ de glicose com aumento do tempo dos animais em confinamento, ocorrendo o inverso com o nível de proteína total. De acordo com VAN SOEST (1994), o metabolismo energético em ruminantes é muito complexo. Os carboidratos solúveis ingeridos são facilmente fermentados pelos microrganismos no rúmen, assim como determinada parte dos carboidratos complexos da parede celular das plantas (hemicelulose e celulose). Os produtos finais da fermentação dos carboidratos são os ácidos graxos voláteis (AGV), principalmente o acético, propiônico e butírico. O aumento de carboidrato solúvel na dieta de ruminante, como no caso de aumento de concentrado, leva a incremento na produção de ácido propiônico, que é o único dos três AGV que é glicogênico, cuja síntese ocorre no fígado, concordando com os dados obtidos no presente trabalho, já que a ração com alta energia apresentava maior proporção de concentrado. Entretanto, mesmo a administração de grandes quantidades de ácido propiônico no rúmen não promove grandes aumentos no nível de glicose sangüínea. De alguma forma, o nível de glicose deve ter aumentado ao longo 
do tempo, devido a maior consumo de matéria seca e energia com o crescimento dos animais. $\mathrm{O}$ teor de proteína total médio $(7,85 \mathrm{~g} \%)$ foi levemente inferior ao encontrado por STEFANOVA e TZANKOVA (1994) de, $9,1 \mathrm{~g} \%$ em bubalinos com 20 meses de idade.

\section{Conclusões}

Os bubalinos apresentaram ganhos de peso diários mais elevados, na medida em que foram alimentados com níveis crescentes de energia na dieta em confinamento.

Os valores de energia metabolizável recomendados por KEARL (1982) para bubalinos em crescimento encontraram-se superestimados, com média de $14,73 \%$ sobre o total de energia metabolizável ingerida.

\section{Agradecimento}

À Fundação de Amparo a Pesquisa do Estado de São Paulo (FAPESP), pelo apoio financeiro a este trabalho de pesquisa.

Ao Prof. Dr. Paulo Cury da Faculdade de Medicina Veterinária e Zootecnia daUNESP, Campus de Botucatu, pelo apoio nas análises estatísticas do trabalho.

\section{Referências Bibliográficas}

AGRICULTURAL AND FOOD RESEARCH COUNCIL AFRC. 1995. Energy and protein requirements of ruminants. Wallingford: CAB Iternational. 157p.

AGRICULTURAL RESEARCH COUNCIL - ARC. 1980. The nutrient requirements of ruminant livestock. London: CAB. $351 \mathrm{p}$.

CHURCH, D.C., POND, W.G. 1977. Bases científicas para 1a nutrición y alimentación de los animales domésticos. Zaragoza: Editorial Acribia. 462p.

DRUDI, A., MATTOS, J.C.A. de, PEREIRA, W. M. et al. 1976. Avaliação do desempenho e do rendimento das carcaças de bubalinos, Bubalus bubalis L., de sobreano, castrados e nãocastrados. Zootecnia, 14(3):139-147.

JORGE, A.M., FONTES, C.A.A., FREITAS, J.A. et al. 1997. Ganho de peso e de carcaça, consumo e conversão alimentar de bovinos e bubalinos, abatidos em dois estádios de maturidade. Rev. bras. zootec., 26(4):806-812.

KEARL, L.C. 1982. Nutrient requirements of ruminant in development contries. Logan: Utah State University. 381p.

KHAN, M.Y., KISHAN, J., LAL, M. et al. Energy requirement of Murrah buffalo for maintenance. In: WORLD BUFFALO CONGRESS, 2, 1988, New Delhi. Proceedings... New Delhi: IBF, 1988. p.238-243.
LORENZONI, W.R., CAMPOS, J., GARCIA, J.A. et al. 1986. Ganhos de peso, eficiência alimentar e qualidade de carcaça de novilhos bubalinos, nelores, holandeses e mestiços holandêsZebu. R. Soc. Bras. Zootec., 15(6):486-497.

MINSON, D.J., STOBBS, T.H., HEGARTY, M.P. et al. 1976. Measuring the nutritive value of pasture plants. In: SHAW, N.H., BRYAN, W.W. (Eds.) Tropical pasture research. Principles and methods. In: Commonwealth Agricultural Bureaux. p.308-337.

MORRISON, D.F. 1967. Multivariate statistical methods. New York: McGraw Hill. 338p.

NATIONAL RESEARCH COUNCIL - NRC. 1989. Nutrient requirements of dairy cattle. Washington, D.C.: National Academy Press. $157 \mathrm{p}$.

RODRIGUES, V.C., ANDRADE, I.F., SOUZA, J.C.D. de et al. Desempenho de bubalinos e bovinos em confinamento. In: REUNIÃO ANUAL DA SOCIEDADE BRASILEIRA DE ZOOTECNIA, 37, 2000, Viçosa. Anais...Viçosa: SBZ, 2000. p.1-3.

SNIFFEN, C.J., O'CONNOR, J.D., VAN SOEST, P.J. et. al. 1992. A net carbohydrate and protein system for evaluating cattle diets: II. Carbohydrate and protein availability. J. Animal Sci., 70(11):3562-3577.

STATSOFT, INC. 1995. Statistica for windows [computer program manual]. Tulsa.

STEFANOVA, S., TZANKOVA, M. Dynamics of some morphological and biochemical blood components in buffaloes in connection with their age. In: WORLD BUFFALO CONGRESS, 4, 1994, São Paulo. Proceedings...São Paulo: ABCB, 1994. p.431-433.

TEIXEIRA, J.C., SILVA, J.F.C., GARCIA, J.A. et al. 1987. Exigências de energia e proteína, composição e área corporal e principais cortes da carcaça em seis grupos genéticos de bovídeos. II. Exigências de energia e proteína. R. Soc. Bras. Zootec., 16(2):181-192.

VAN SOEST, P.J. 1994. Nutritional ecology of the ruminant. 2.ed. Ithaca: Cornell University Press. 476p.

VELLOSO, L., SCHALCH, E., FRANZOLIN NETO, R. et al. 1994. Desempenho comparativo de zebuínos Nelore e bubalinos Mediterrâneo em regime de confinamento. R. Soc. Bras. Zootec., 23(2):236-241.

VILlARES, J.B., SILVEIRA, A.C., RAMOS, A.A. 1979. Conversão de alimentos de bubalinos Mediterrâneo, Jafarabadie Murrah. Bubalinos. Araçatuba: Fundação Cargill. p.147-169.

ZAR, J.H. 1984. Biostatistical analysis. 2.ed. Englewood Cliffs: Prentice Hall. 718p. 